\title{
Environmental and genetic aspects of survival and early liveweight in Western Australian Merino sheep
}

\author{
S.W.P. Cloete ${ }^{12 \#}$, J.C. Greeff ${ }^{2}$ and R.P. Lewer $^{3}$ \\ ${ }^{1}$ Animal Production Division, Elsenburg ADI, Private Bag X1, Elsenburg 7607, South Africa. \\ ${ }^{2}$ Great Southern Agricultural Research Institute, 10 Dore street, Katanning 6317, WA, Australia. \\ ${ }^{3}$ Queensland Department of Primary Industries, Locked Bag 4, Moorooka 4105, QLD, Australia.
}

\begin{abstract}
(Co)variance estimates for birth weight, pre-weaning lamb survival and weaning weight were obtained for Merino lambs derived from 16 bloodlines. Between bloodline variance ratios ( \pm s.e.) amounted to $0.10 \pm$ 0.04 for lamb birth weight, $0.053 \pm 0.036$ for lamb survival (logit scale) and $0.18 \pm 0.07$ for lamb weaning weight. Direct additive genetic variances for weaning weight - expressed as a ratio of the total phenotypic variance within bloodlines $\left(\mathrm{h}^{2}\right.$, direct heritability) - were estimated at $0.18 \pm 0.02$ for birth weight, $0.094 \pm$ 0.020 (logit scale) for pre-weaning survival and $0.30 \pm 0.02$ for weaning weight. Corresponding maternal genetic variance ratios $\left(\mathrm{m}^{2}\right)$ were estimated at $0.15 \pm 0.02$ for birth weight and $0.08 \pm 0.02$ for weaning weight. It was not significant in the case of lamb survival. Maternal permanent environmental variance ratios $\left(\mathrm{c}^{2}\right)$ amounted to $0.08 \pm 0.02$ for birth weight, $0.044 \pm 0.018$ for lamb survival (logit scale) and $0.07 \pm$ 0.02 for weaning weight. These results were discussed with reference to sheep production.
\end{abstract}

Keywords: sheep, genetics, survival, weaning weight

${ }^{\#}$ Author to whom the correspondence should be addressed; e-mail: schalkc@wcape.agric.za

\section{Introduction}

The level of production in sheep reflects the genes that the animal has inherited from both its parents as well as a mixture of seasonal and husbandry factors peculiar to the prevailing environment (Lewis \& Beatson, 1999). Maternal influences are evident early in life but tend to disappear with an increase in age (Snyman et al., 1995). Maternal influences can be derived from the genotype of the dam (maternal additive genetic effects) or from factors consistent between lambings but not genetic in origin, also referred to as maternal permanent environmental effects (Lewis \& Beatson, 1999). The advent of sophisticated software has enabled analysts to fit extended models to data obtained from livestock breeding operations (Meyer, 1989). This paper reports genetic and environmental influences on live weight at birth and weaning, as well as survival prior to weaning, in a resource flock maintained at the Great Southern Agricultural Research Institute near Katanning in Western Australia (Lewer, 1993).

\section{Material and methods}

The data used in this study were from a resource flock held at Katanning in Western Australia. A total of four strains, each consisting of four daughter studs, were represented in the data. Sixteen studs or bloodlines were thus included. Of these, 12 bloodlines (representing three strains) were available from the beginning of the trial period, while 4 new bloodlines (representative of one strain) were introduced during 1986. Each bloodline was represented by approximately 80 ewes and four rams within years. New rams were acquired from within the bloodlines each year to keep the base flock representative of the genetic material available in the industry. One ram of each bloodline was retained for mating in each following year to provide sire links between years. Replacement ewes were selected at random from the available candidates (Lewer, 1993). The climate at the experimental site is typical of a Mediterranean environment. The longterm annual precipitation at the site averages $500 \mathrm{~mm}, 80 \%$ of which is recorded during the winter months between April and September. The bloodlines were maintained in a single flock, except for mating during October-November and lambing during March-April. During these periods, the animals were maintained in sire groups on small paddocks. These groups were subsequently pooled to form larger flocks as soon as practically possible after the peak lambing period had passed. All flocks mostly utilised dryland grass-clover paddocks on a set stock basis. Cereal stubble and fodder crops were seasonally available.

Data, that were recorded over a 12-year period from 1982 to 1993, included lamb birth weight (12 858 records), survival to weaning (12 932 records) and lamb weaning weight (11 073 records). The discrepancy in numbers between birth weight and survival resulted from lambs that were mutilated by 
scavengers, making it impossible to determine birth weight accurately. Individual weaning age averaged ( \pm s.d.) $106 \pm 27 \mathrm{~d}$ and ranged from 42 to $146 \mathrm{~d}$. The large difference in age at weaning resulted from differences in managerial practices from year to year. Environmental factors affecting the production traits included year of birth (1982-1993), sex (male or female), age of dam (2 to 4+ years) and birth type (single or pooled multiples). The paddock of birth and the identity of the sire and dam of lambs were recorded for individuals. This information enabled linkage back to the strain and bloodline of origin.

The ASREML program (Gilmour et al., 1999) was used for analysis of the data, and to estimate variance components in univariate analyses. The first analysis involved fitting various combinations of fixed effects (including the linear regression of weaning weight on weaning age) to obtain an operational model. Random trends other than linear (splines) for year and age-of-dam means, as well as deviations from it, were also fitted where applicable at this stage. Effects found to be significant $(\mathrm{P}<0.05)$ in these preliminary analyses were included in subsequent analyses. Random terms were then added to the operational model, resulting in the following models for analyses (in matrix notation):

$\mathrm{y}=\mathrm{Xb}+\mathrm{Z}_{1} \mathrm{p}+\mathrm{Z}_{2} \mathrm{bl}+\mathrm{Z}_{3} \mathrm{a}+\mathrm{e}$

$\mathrm{y}=\mathrm{Xb}+\mathrm{Z}_{1} \mathrm{p}+\mathrm{Z}_{2} \mathrm{bl}+\mathrm{Z}_{3} \mathrm{a}+\mathrm{Z}_{4} \mathrm{c}+\mathrm{e}$

$\mathrm{y}=\mathrm{Xb}+\mathrm{Z}_{1} \mathrm{p}+\mathrm{Z}_{2} \mathrm{bl}+\mathrm{Z}_{3} \mathrm{a}+\mathrm{Z}_{4} \mathrm{~m}+\mathrm{e}$

[Correlation $(\mathrm{a}, \mathrm{m})=0]$

$\mathrm{y}=\mathrm{Xb}+\mathrm{Z}_{1} \mathrm{p}+\mathrm{Z}_{2} \mathrm{bl}+\mathrm{Z}_{3} \mathrm{a}+\mathrm{Z}_{4} \mathrm{~m}+\mathrm{Z}_{5} \mathrm{c}+\mathrm{e}$

[Correlation $(\mathrm{a}, \mathrm{m})=0]$

$\mathrm{y}=\mathrm{Xb}+\mathrm{Z}_{1} \mathrm{p}+\mathrm{Z}_{2} \mathrm{bl}+\mathrm{Z}_{3} \mathrm{a}+\mathrm{Z}_{4} \mathrm{~m}+\mathrm{e}$

[Correlation $(\mathrm{a}, \mathrm{m})=\mathrm{A} \sigma_{\mathrm{am}}$ ]

$\mathrm{y}=\mathrm{Xb}+\mathrm{Z}_{1} \mathrm{p}+\mathrm{Z}_{2} \mathrm{bl}+\mathrm{Z}_{3} \mathrm{a}+\mathrm{Z}_{4} \mathrm{~m}+\mathrm{Z}_{5} \mathrm{c}+\mathrm{e}$

[Correlation $\left.(\mathrm{a}, \mathrm{m})=\mathrm{A} \sigma_{\mathrm{am}}\right]$

With y being a vector of observations for live weight traits or survival; $b, p, b l, a, m$ and $c$ vectors of fixed effects, between lambing paddock variances, between bloodline variances, direct genetic variances, maternal genetic variances and maternal permanent environmental variances respectively; $X, Z_{1}, Z_{2}, Z_{3}, Z_{4}$ and $Z_{5}$ the corresponding incidence matrices relating the respective effects to $y$; e the vector of residuals; $A$ the numerator relationship matrix, and $\sigma_{\mathrm{am}}$ the correlation between direct genetic and maternal effects.

It was assumed that

$\mathrm{V}(\mathrm{p})=\mathrm{I} \sigma_{\mathrm{p}}^{2} ; \mathrm{V}(\mathrm{bl})=\mathrm{I} \sigma_{\mathrm{bl}}^{2} ; \mathrm{V}(\mathrm{a})=\mathrm{A} \sigma_{\mathrm{a}}^{2} ; \mathrm{V}(\mathrm{m})=\mathrm{A} \sigma_{\mathrm{m}}^{2} ; \mathrm{V}(\mathrm{c})=\mathrm{A} \sigma_{\mathrm{c}}^{2} ; \mathrm{V}(\mathrm{e})=\mathrm{I} \sigma_{\mathrm{e}}^{2}$,

With I being identity matrixes; $I \sigma_{p}^{2}, \sigma_{b l}^{2}, \sigma_{a}^{2}, \sigma_{m}^{2}, \sigma_{c}^{2}$ and $\sigma_{e}^{2}$ the between paddock variance, the between bloodline variance, direct genetic variance, maternal genetic variance and the maternal permanent environmental variance and environmental (residual) variance respectively.

Lambing paddocks and bloodlines were regarded as random for these analyses to enable the calculation of variance ratios for these effects, but also because they represented a random sample of the available paddocks and bloodlines. These analyses yielded estimates of the genetic and permanent environmental variances within bloodlines. Ratios reported for direct additive genetic, maternal genetic as well as maternal permanent environmental variances thus also represent within-bloodline estimates. Log likelihood tests were conducted to determine the most suitable model for each trait in uni-variate analyses (Snyman et al., 1996). Variance ratios were computed for random effects included in these analyses, which included the effects of bloodline and lambing paddock. The latter variances were expressed relative to the total phenotypic variation. In the case of lamb survival, the best model according to the log-likelihood ratios was refitted, using logit and probit link functions to link the binomially distributed data to the normal distribution. Results from these analyses were essentially similar, as was also found by Lopez-Villalobos \& Garrick (1999) and Morris et al. (2000), and therefore only the results of the logit analysis were presented. 


\section{Results}

Sires and dams contributing progeny to the data numbered 442 and 4577 respectively, and 87 lambing paddocks were used during the experiment. Birth weight records averaged ( \pm s.d.) $4.6 \pm 0.9 \mathrm{~kg}$, with a range of 2.1-8.6 kg. Corresponding figures for weaning weight were $23.2 \pm 5.3 \mathrm{~kg}$, with a range of 8.0-46.0 kg. The effects of sex, birth type and age of dam on the respective traits are given in Table 1 . In general, male lambs were $6.3 \%$ heavier than females at birth and $6.7 \%$ heavier at weaning $(\mathrm{P}<0.05)$. Singles were $20.0 \%$ heavier than multiples at birth and $19.3 \%$ heavier at weaning $(\mathrm{P}<0.01)$. Birth and weaning weight generally increased with an increased ewe age. Significant deviations from a linear trend were observed as indicated by improvements in the fit of the model of analysis (i.e. improved log likelihood ratio) by the inclusion of a quadratic term. The survival of male lambs and multiples was compromised ( $\mathrm{P}<$ $0.05)$ relative to that of females and singles. Lamb survival showed a linear improvement with an increase in ewe age.

Table 1 Least squares means ( \pm s.e.) for birth weight, lamb survival prior to weaning (transformed to the logit scale) and weaning weight in Merino lambs. Back transformed means for survival are given in parentheses. Weaning age was set to 100 days in the case of weaning weight.

\begin{tabular}{lccc}
\hline Effect & \multicolumn{3}{c}{ Trait } \\
\cline { 2 - 4 } & Birth weight & Lamb survival & Weaning weight \\
\hline Overall mean & $4.3 \pm 0.1$ & $1.78 \pm 0.09(0.86)$ & $21.3 \pm 2.5$ \\
Sex & & & \\
Male & $4.5 \pm 0.2$ & $1.89 \pm 0.10(0.87)$ & $22.3 \pm 2.5$ \\
Female & $4.2 \pm 0.2$ & $1.66 \pm 0.09(0.84)$ & $20.9 \pm 2.5$ \\
Birth type & & & \\
Single & $4.9 \pm 0.2$ & $2.20 \pm 0.12(0.90)$ & $23.5 \pm 2.5$ \\
Multiple & $3.9 \pm 0.2$ & $1.35 \pm 0.12(0.80)$ & $19.7 \pm 2.5$ \\
Age of dam & & & \\
2 years & $4.1 \pm 0.2$ & $1.61 \pm 0.10(0.83)$ & $21.0 \pm 2.5$ \\
3 years & $4.3 \pm 0.2$ & $1.71 \pm 0.09(0.85)$ & $22.0 \pm 2.5$ \\
4 years & $4.4 \pm 0.2$ & $1.82 \pm 0.09(0.86)$ & $22.4 \pm 2.5$ \\
5 years & $4.4 \pm 0.2$ & $1.92 \pm 0.10(0.87)$ & $22.1 \pm 2.5$ \\
\hline
\end{tabular}

Log likelihood values were obtained for single-trait analyses of the respective traits. Additional random variance ratios (apart from lambing paddock and bloodlines) that were considered (in order of inclusion) were the direct additive animal variance $\left(\mathrm{h}^{2}\right)$, maternal variance $\left(\mathrm{m}^{2}\right)$, the maternal permanent environmental variances $\left(\mathrm{c}^{2}\right)$ and the correlation between $\mathrm{h}^{2}$ and $\mathrm{m}^{2}$. A model that included $\mathrm{h}^{2}, \mathrm{~m}^{2}$ and $\mathrm{c}^{2}$ fitted the data best in the case of birth weight and weaning weight (Table 2). Only $h^{2}$ and $c^{2}$ were retained in the analysis on lamb survival prior to weaning.

Table 2 Log likelihood ratios for birth weight, preweaning lamb survival and weaning weight in Merino lambs under different models. The models are numbered as described under material and methods. Bold italics indicate the "best" model.

\begin{tabular}{lccc}
\hline Model fitted & \multicolumn{3}{c}{ Trait } \\
\cline { 2 - 4 } & Birth weight & Lamb survival & Weaning weight \\
\hline Fixed effects only & -2549.09 & 7351.39 & -19578.6 \\
Model 1 & -2113.35 & 7439.94 & -19196.9 \\
Model 2 & -1899.73 & 7446.24 & -19113.0 \\
Model 3 & -1928.55 & 7451.88 & -19113.3 \\
Model 4 & $\mathbf{- 1 8 8 6 . 5 4}$ & 7451.89 & $\mathbf{- 1 9 0 9 9 . 8}$ \\
Model 5 & -1897.77 & 7452.49 & -19108.9 \\
Model 6 & -1885.52 & 7453.17 & -19106.3 \\
\hline
\end{tabular}

The random variance associated with lambing paddock resulted in a small but significant $(\mathrm{P}<0.05)$ improvement of the log likelihood ratios in the case of birth weight and lamb survival. Variance ratios $( \pm$ s.e.) amounted to $0.002 \pm 0.001$ in the case of birth weight expressed relative to the total phenotypic variance. The corresponding estimate for lamb preweaning survival was $0.008 \pm 0.004$. No significant 
lambing paddock variance was found in weaning weight. Bloodline differences accounted for $10 \%$ of the total phenotypic variance in birth weight, $5 \%$ of the total phenotypic variance in survival prior to weaning and $18 \%$ of the total phenotypic variance in weaning weight (Table 3). Estimates for $\mathrm{h}^{2}$ ranged from 0.09 in the case of lamb survival to 0.30 for lamb weaning weight. Maternal genetic variance ratios $\left(\mathrm{m}^{2}\right)$ were present for birth and weaning weight, amounting to 0.15 and 0.08 respectively. No evidence of maternal genetic variation was detected for lamb survival, but a significant $(\mathrm{P}<0.05)$ maternal permanent environmental effect $\left(c^{2}\right)$ was detected. Significant $c^{2}$ effects were also present for lamb birth and weaning weight.

Table 3 Variances and ratios for direct additive genetic variance $\left(\mathrm{h}^{2}\right)$, maternal genetic variance $\left(\mathrm{m}^{2}\right)$ and maternal permanent environmental variance $\left(\mathrm{c}^{2}\right)$ for lambs born in the Katanning Merino flock. The logit transformation was employed in the case of lamb survival.

\begin{tabular}{lccc}
\hline Effect fitted & \multicolumn{3}{c}{ Trait } \\
\cline { 2 - 4 } & Birth weight & Lamb survival & Weaning weight \\
\hline Variance between paddocks & 0.0012 & 0.034 & - \\
Variance between bloodlines & 0.0617 & 0.215 & 2.819 \\
Variance within bloodlines: & 0.5486 & 3.816 & 12.680 \\
Residual & 0.3226 & 3.290 & 7.019 \\
Direct additive & 0.1014 & 0.359 & 3.766 \\
Maternal additive & 0.0812 & - & 0.959 \\
Maternal permanent environmental & 0.0434 & 0.167 & 0.936 \\
Total phenotypic variance & 0.6180 & 4.065 & 15.499 \\
Between bloodline variance ratio & & & \\
Within bloodline variance ratios & $0.10 \pm 0.04$ & $0.053 \pm 0.036$ & $0.18 \pm 0.07$ \\
$\mathrm{~h}^{2}$ & & & \\
$\mathrm{~m}^{2}$ & $0.18 \pm 0.02$ & $0.094 \pm 0.020$ & $0.30 \pm 0.02$ \\
$\mathrm{c}^{2}$ & $0.15 \pm 0.02$ & - & $0.08 \pm 0.02$ \\
\hline
\end{tabular}

\section{Discussion}

The effects of the various environmental influences (birth year, sex, age of dam, birth type, weaning age) on birth and weaning weight will not be discussed in detail in this paper. These effects accorded with those generally reported in comparable literature as far as size, direction and magnitude were concerned (Cloete et al. 1998). The same is true for the factors that influenced lamb survival, which agreed with findings reviewed by Alexander (1984). Although these effects and interactions among them may be of statistical importance in the specification of appropriate models for analysis, it is not always of practical significance. It is probably important to note that the short-term environment imposed by lambing paddock did have an effect, albeit less than $1 \%$ of the overall environmental mean, on lamb birth weight and survival. Although speculative, such effects could possibly be related to pasture quantity and quality, as well as to the micro-environment created by the topography and availability of shelter inherent to specific paddocks in the case of lamb survival.

It was clear that significant variation existed for all traits between the medium wool bloodlines included in the study. Expressed as a ratio of the across-bloodline phenotypic variation, the between bloodline variance components for lamb survival amounted to only 5\%. In the case of live weight traits, the between-bloodline variance components were higher, approaching $20 \%$ for lamb weaning weight. Withinbloodline estimates of genetic variation, however, exceeded the variation introduced by bloodlines for all traits. The scope for Western Australian medium wool producers to exploit between-bloodline variation in their selection strategies thus seems to be limited, with the possible exception of lamb weaning weight.

Literature estimates for the $\mathrm{h}^{2}$ of birth weight ranged from 0.03 to 0.23 (Table 4). Corresponding ranges were 0.02 to 0.22 for $\mathrm{m}^{2}$ and 0.02 to 0.41 for $\mathrm{c}^{2}$. The estimates derived from this study accorded with these values. It was also in good agreement with results reported by Mortimer and Atkins (1995), the only other study on Merinos that could be found. 
Table 4 Summary of reported values for animal model direct additive $\left(\mathrm{h}^{2}\right)$, maternal $\left(\mathrm{m}^{2}\right)$ and permanent environmental $\left(\mathrm{c}^{2}\right)$ variance ratios for birth weight in sheep

\begin{tabular}{lcccl}
\hline Breed & \multicolumn{3}{c}{ Variance ratio } & \multicolumn{2}{c}{ Reference } \\
\cline { 2 - 5 } & $\mathrm{h}^{2}$ & $\mathrm{~m}^{2}$ & $\mathrm{c}^{2}$ & \\
\hline Merino & 0.23 & 0.14 & 0.12 & Mortimer \& Atkins (1995) \\
Dohne Merino & 0.04 & 0.10 & 0.17 & Cloete et al. $(1998)$ \\
Crossbred & 0.08 & - & 0.41 & Conington et al. $(1995)$ \\
Crossbred & 0.24 & 0.08 & 0.57 & Hall et al. $(1995)$ \\
Romanov & 0.04 & 0.22 & 0.10 & Maria et al. $(1993)$ \\
Afrino & 0.33 & 0.17 & - & Snyman et al. $(1995)$ \\
Various & $0.07-0.39$ & $0.13-0.31$ & $0.32-0.37$ & Tosh \& Kemp (1994) \\
Various & $0.16-0.22$ & $0.18-0.24$ & $0.09-0.11$ & Bromley et al. 2000 \\
Dormer & 0.13 & 0.21 & - & Van Wyk et al. $(1993)$ \\
Baluchi & $0.05-0.06$ & $0.02-0.04$ & $0.02-0.04$ & Yasdi et al. $(1997)$ \\
Tropical sheep & 0.03 & 0.13 & 0.22 & Pitono \& James $(1995)$ \\
\hline
\end{tabular}

Heritability estimates for lamb survival are scarce in the literature. The binomial distribution of survival data, as well as the computational difficulties associated with it complicates such analyses. Threshold model analysis of survival by sire-maternal grandsire models yielded heritability estimates of essentially zero (Snyman et al., 1998; Olivier et al., 1998). Other studies yielded slightly higher estimates (Konstantinov et al., 1994), but still reported limited genetic variation. Analysts have rightfully concluded from these results that the prospects of genetic progress in lamb survival are highly unlikely. A significant $\mathrm{h}^{2}$ estimate was computed in the present study. This estimate accorded with a value of 0.11 reported for crossbred lambs by Hall et al. (1995). It was, however, higher than corresponding estimates of 0.01 recently reported by Lopez-Villalobos and Garrick (1999) and that of 0.01 to 0.03 reported by Morris et al. (2000). Hall et al. (1995) reported a litter variance - this could also be expressed as a maternal temporary environmental effect (Lewis \& Beatson 1999) - amounting to 19\% of the total phenotypic variance. This estimate differs from the $\mathrm{c}^{2}$ estimate in the present study in the sense that it involved lambs born in the same litter in fecund Booroola crossbred ewes. Results from the present study involved the association between lambs born to the same dam over years in Merino sheep with a fairly low fecundity. Lopez-Villalobos \& Garrick (1999) correspondingly reported a $c^{2}$ variance ratio of 0.09 for lamb survival in their study after the logit transformation, which tends to be higher than the present estimate. Corresponding estimates of $\mathrm{c}^{2}$ reported by Morris et al. (2000) amounted to between 0.06 and 0.10 for preweaning survival. Both literature sources concluded that maternal environment contributed most to the repeatability of lamb survival when viewed as a trait of the dam. In the study by Burfening (1993) $\mathrm{h}^{2}$ estimates for lamb survival in Rambouillet, Targhee and Columbia sheep ranged from 0.002 to 0.051 on the normal scale. Corresponding $\mathrm{m}^{2}$ estimates ranged from 0.052 to 0.112. Corresponding estimates from New Zealand ranged from 0.035 to 0.095 (Lopez-Villalobos \& Garrick, 1999; Morris et al., 2000) after the logit transformation. Based on parameter estimates cited in the literature as well as those of the present study, most analysts would agree that the scope for selection for increased lamb survival rate is limited, although some genetic variation appears to exist. Yet, it has to be conceded that successes with regard to genetic gains in lamb survival and/or ewe rearing ability were reported in the literature (Donnelly, 1982; Haughey, 1983; Knight et al., 1998; Cloete \& Scholtz, 1998). This may also be applicable to the flock under consideration, provided that a workable selection strategy can be devised.

Literature estimates for the $\mathrm{h}^{2}$ of weaning weight ranged from 0.06 to 0.39 (Table 4). Corresponding ranges were 0.03 to 0.48 for $\mathrm{m}^{2}$ and 0.02 to 0.41 for $\mathrm{c}^{2}$. Estimates derived from the present study accorded with these values and were also in good agreement with results from four previous studies with Merino sheep.

No significant correlation was found between $\mathrm{h}^{2}$ and $\mathrm{m}^{2}$ variance ratios in this study. In this respect, there is a great deal of variation in the literature. Estimates for this correlation vary from fairly high and negative (Van Wyk et al., 1993; Maria et al., 1993, Hagger \& Schneeberger, 1995; Mortimer \& Atkins, 1995; Notter, 1998; Neser et al., 1998; 2000; Grey et al., 1999) to very variable, including positive and negative estimates (Burfening \& Kress, 1993: -0.41 to 0.55; Tosh \& Kemp, 1994: -0.74 to 0.43; Lewis \& Beatson, 1999: -0.78 to 0.30). Notter (1998), on the other hand, found no adverse genetic relationships between $\mathrm{h}^{2}$ and $\mathrm{m}^{2}$ variance ratios, while this relationship was positive in the study of Swan \& Hickson 
(1994) on Australian Merinos. The obvious disadvantages of a highly negative correlation between direct and maternal variances to selection are noted in the literature (cf. Lewis \& Beatson, 1999). In this regard, Robinson (1996) pointed out that the negative correlation between direct and maternal additive variances in beef cattle could result from other effects in the data rather than a true negative genetic relationship. This may also hold true for sheep populations, as was thoroughly discussed by Notter \& Hough (1997) as well as Lewis \& Beatson (1999).

Table 5 Summary of reported values for animal model direct additive $\left(\mathrm{h}^{2}\right)$, maternal $\left(\mathrm{m}^{2}\right)$ and permanent environmental $\left(\mathrm{c}^{2}\right)$ variance ratios for weaning weight in sheep

\begin{tabular}{|c|c|c|c|c|}
\hline \multirow[t]{2}{*}{ Breed } & \multicolumn{3}{|c|}{ Variance ratio } & \multirow[t]{2}{*}{ Reference } \\
\hline & $\mathrm{h}^{2}$ & $\mathrm{~m}^{2}$ & $\mathrm{c}^{2}$ & \\
\hline Merino & $0.19-0.25$ & $0.14-0.23$ & 0.02 & Hickson et al. (1995) \\
\hline Merino & 0.27 & 0.11 & 0.07 & Mortimer \& Atkins (1995) \\
\hline Merino & 0.14 & 0.11 & 0.05 & Snyman et al. (1996) \\
\hline Merino & 0.24 & 0.23 & - & Swan \& Hickson (1994) \\
\hline Dohne Merino & 0.06 & - & 0.21 & Cloete et al. (1998) \\
\hline SA Mutton Merino & $0.13-0.35$ & 0.17 & 0.07 & Neser et al. (1998) \\
\hline SA Mutton Merino & $0.14-0.19$ & $0.09-0.20$ & 0.10 & Neser et al. (2000) \\
\hline SA Mutton Merino & 0.32 & 0.15 & 0.07 & Grey et al. (1999) \\
\hline Various & $0.09-0.22$ & $0.07-0.48$ & - & Burfening \& Kress (1993) \\
\hline Various & $0.21-0.27$ & $0.03-0.04$ & $0.39-0.41$ & Clarke et al. (1998) \\
\hline Crossbred & 0.12 & - & 0.18 & Conington et al. (1995) \\
\hline Crossbred & 0.19 & 0.05 & 0.15 & Hall et al. (1995) \\
\hline Crossbred & 0.12 & 0.17 & 0.10 & Larsgard \& Olesen (1998) \\
\hline Coopworth & $0.03-0.37$ & $0.04-0.15$ & $0.0-0.09$ & Lewis \& Beatson (1999) \\
\hline Romanov & 0.34 & 0.25 & 0.00 & Maria et al. (1993) \\
\hline Dorper & $0.11-0.30$ & $0.07-0.20$ & - & Neser et al. (1995) \\
\hline Targhee & $0.01-0.10$ & $0.05-0.11$ & $0.08-0.09$ & Notter \& Hough (1997) \\
\hline Various & $0.15-0.21$ & $0.04-0.12$ & $0.06-0.13$ & Notter (1998) \\
\hline Afrino & 0.33 & 0.17 & - & Snyman et al. (1995) \\
\hline Various & $0.14-0.39$ & $0.02-0.19$ & $0.12-0.20$ & Tosh \& Kemp (1994) \\
\hline Dormer & 0.13 & 0.21 & - & Van Wyk et al. (1995) \\
\hline Baluchi & $0.13-0.19$ & 0.03 & $0.04-0.07$ & Yasdi et al. (1997) \\
\hline Tropical sheep & 0.06 & 0.09 & 0.14 & Pitono \& James (1995) \\
\hline
\end{tabular}

\section{Conclusions}

Variance ratios for all traits in question were broadly in accordance with literature values cited. Lamb weaning weight and survival prior to weaning were directly related to total weight of lamb weaned per breeding ewe, which is regarded as the best indicator of intrinsic reproduction rate (Olivier, 1999). Both traits seemed to exhibit a measure of genetic variation that could contribute to an improvement in lamb output in the flock under consideration. The value of direct and maternal breeding values for weaning weight in a selection objective would depend strongly on the production system employed. It would, for instance, be valuable in slaughter lamb production systems, but of lesser importance in wool production systems. It is appropriate to mention that weaning weight is considered to be instrumental in the improvement of ewe reproduction by the South African Small Stock Improvement Scheme for woolproducing and dual purpose breeds (Olivier, 1999).

\section{Acknowledgement}

The research was undertaken while the senior author worked as a visiting scientist at the Great Southern Research Institute. The authors are grateful to the Western Australian Department of Agriculture for the provision of funds for traveling and subsistence expenses for this purpose. The authors also gratefully acknowledge the efforts of those responsible for the care and maintenance of the breeding flock, as well as G. Cox and A. Jowett for their efforts in capturing and editing the data used in the analysis. 


\section{References}

Alexander, G., 1984. Constraints to lamb survival. In: 'Reproduction in sheep'. Eds. D.R. Lindsay and D.T. Pearce. Australian Academy of Science in conjunction with the Australian Wool Corporation: Canberra, Australia. pp. 199-209.

Bromley, C.M., Snowder, G.D. \& Van Vleck, L.D., 2000. Genetic parameters among weight, prolificacy, and wool traits of Columbia, Polypay, Rambioullet, and Targhee sheep. J. Anim. Sci. 78, 846-858.

Burfening, P.J., 1993. Direct and maternal effects on lamb survival. Small Rumin. Res. 11, 267-274.

Burfening, P.J. \& Kress, D.D., 1993. Direct and maternal effects on birth and weaning weight in sheep. Small Rumin. Res. 10, 153-163.

Clarke, J.N., Nicoll, G.B. \& Mowat, C.M., 1998. Genetic parameters for live weight and live animal ultrasound fat and eye muscle dimensions in a synthetic terminal sire breed. Proc. N. Z. Soc. Anim. Prod. 58, 140-142.

Cloete, S.W.P. \& Scholtz, A.J., 1998. Lamb survival in relation to lambing and neonatal behaviour in medium wool Merino lines divergently selected for multiple rearing ability. Aust. J. Exp. Agric. 38, 801-811.

Cloete, S.W.P., Scholtz, A.J. \& Aucamp, B.B., 1998. Environmental effects, heritability estimates and genetic trends in a Western Cape Dohne Merino nucleus flock. S. Afr. J. Anim. Sci. 28, 185-195.

Conington, J., Bishop, S.C., Waterhouse, A. \& Simm, G., 1995. A genetic analysis of early growth and ultrasonic measurements in hill sheep. Anim. Sci. 61, 85-93.

Donnelly, F.B., 1982. A practical attempt to breed for better lamb survival. Proc. Aust. Soc. Anim. Prod. $14,30-32$.

Fogarty, N.M., 1995. Genetic parameters for live weight, fat and muscle measurements, wool production and reproduction in sheep: a review. Anim. Breed. Abstr. 63, 101-143.

Gilmour, A.R., Cullis, B.R., Welham, S.J. \& Thompson, R., 1999. ASREML - Reference manuel. NSW Agriculture Biometric Bulletin No. 3. NSW Agriculture, Orange Agricultural Institute, Forest Road, Orange 2800, NSW, Australia.

Grey, H.Q., Neser, F.W.C., Erasmus, G.J. \& van Wyk, J.B., 1999. Genetic trends in a South African Mutton Merino nucleus breeding scheme. S. Afr. J. Anim. Sci. 29, 48-53.

Hagger, C. \& Schneeberger, M., 1995. Influences of amount of pedigree information on computing time and of model assumptions on Restricted Maximum-Likelihood estimates of population parameters in Swiss Black-Brown Mountain sheep. J. Anim. Sci. 73, 2213-2219.

Hall, D.G., Fogarty, N.M. \& Gilmour, A.R., 1995. Performance of crossbred progeny of Trangie fertility Merino and Booroola Merino rams and Poll Dorset ewes. 1. Lamb birth weight, survival and growth. Aust. J. Exp. Agric. 35, 1069-1074.

Haughey, K.G., 1983. Selective breeding for rearing ability as an aid to improving lamb survival. Aust. Vet. J. 60, 361-363.

Hickson, J.D., Swan, A.A., Kinghorn, B.P. \& Piper, L.R., 1995. Maternal effects at different ages in Merino sheep. Proc. Aust. Assoc. Anim. Breed. Gen. 11, 416-420.

Knight, T.W., Lynch, P.R., Hall, D.R.H. \& Hockey, H-U.P., 1988. Identification of factors contributing to the improved lamb survival in Marshall Romney sheep. N. Z. J. Agric. Res. 31,259-271.

Konstantinov, K.V., Erasmus, G.J. \& van Wyk, J.B., 1994. Evaluation of Dormer sires for litter size and lamb mortality using a threshold model. S. Afr. J. Anim. Sci. 24,119-121.

Larsgard, A.G. \& Olesen, I., 1998. Genetic parameters for direct and maternal effects on weights and ultrasonic muscle and fat depth of lambs. Livest. Prod. Sci. 55, 273-278.

Lewer, L.R., 1993. Katanning base flock. In: Merino genetic resource flocks in Australia. Eds: RW Ponzoni and DR Gifford. Proc. Nat. Workshop, Turretfield Research Centre, Rosedale, South Australia. pp 10-14.

Lewis, R.M. \& Beatson, P.R., 1999. Choosing maternal effect models to estimate (co)variances for live and fleece weight in New Zealand Coopworth sheep. Livest. Prod. Sci. 58, 137-150.

Lopez-Villalobos, N. \& Garrick, D.J., 1999. Genetic parameter estimates for lamb survival in Romney sheep. Proc. N. Z. Soc. Anim. Prod. 59, 121-124.

Maria, G.A., Boldman, K.G. and van Vleck, L.D., 1993. Estimates of variances due to direct and maternal effects for growth traits of Romanov sheep. J. Anim. Sci. 71, 845-849.

Meyer, K. 1989. Restricted maximum likelihood to estimate variance components for animal models with several random effects using a derivative free algorithm. Gen., Select. Evol. 21, 317-340. 
Morris. C.A., Hickey, S.M. \& Clarke, J.N., 2000. Genetic and environmental factors affecting lamb survival at birth and through to weaning. N. Z. J. Agric. Res. 43, 515-524.

Mortimer, S.I. \& Atkins, K.D., 1995. Maternal effects influence growth traits in Merino sheep. Proc. Aust. Assoc. Anim. Breed. Gen. 11, 421-424.

Neser, F.W.C., Erasmus, G.J., van Wyk, J.B. \& van Deventer, C.S., 1998. An investigation into possible genotype X environment interactions for weaning weight in South African Mutton Merino sheep. S. Afr. J. Anim. Sci. 28, 179-184.

Neser, F.W.C., Erasmus, G.J. \& van Wyk, J.B., 2000. Genetic studies on the South African Mutton Merino: growth traits. S. Afr. J. Anim. Sci. 30, 172-177.

Neser, F.W.C., Konstantinov, K.V. \& Erasmus, G.J., 1995. Estimated genetic trends for weaning weight in three Dorper lines with different selection criteria. S. Afr. J. Anim. Sci. 25, 65-69.

Notter D.R., 1998. The U.S. National sheep improvement program: Across flock genetic evaluations and new trait development. J. Anim. Sci. 76, 2324-2330.

Notter, D.R. \& Hough, J.D., 1997. Genetic parameters for growth and fleece characteristics in Targhee sheep. J. Anim. Sci. 75, 1729-1737.

Olivier, J.J., 1999. The South African Merino performance testing scheme. Proc. Assoc. Advmnt Anim. Breed. Gen. 13, 119-124.

Olivier, W.J., Snyman, M.A., van Wyk, J.B. \& Erasmus, G.J., 1998. Genetic parameters for fitness traits in South African Merino sheep. Livest. Prod. Sci. 56, 71-77.

Pitono, A.D. \& James, J.W., 1995. Estimates of genetic parameters for lamb weights and growth traits of tropical sheep. Proc. Aust. Assoc. Anim. Breed. Gen. 11, $425-429$.

Robinson, D.L., 1996. Estimation and interpretation of direct and maternal genetic parameters for weights of Australian Angus cattle. Livest. Prod. Sci. 45, 1-11.

Snyman, M.A., Erasmus, G.J. \& van Wyk, J.B., 1995. Direct and maternal (co)variance components and heritability estimates for body weight at different ages and fleece traits in Afrino sheep. Livest. Prod. Sci. 44, 229-235.

Snyman, M.A., Erasmus, G.J. \& van Wyk, J.B., 1998. The possible genetic improvement of reproduction and survival rate in Afrino sheep using a threshold model. S. Afr. J. Anim. Sci. 28,120-124.

Snyman, M.A., Olivier, J.J. \& Olivier, W.J., 1996. Variance components and genetic parameters for body weight and fleece traits of Merino sheep in an arid environment. S. Afr. J. Anim. Sci. 26, 11-14.

Swan, A.A. \& Hickson, J.D., 1994. Maternal effects in Australian Merinos. Proc. $5^{\text {th }}$ World Cong. Gen. Appl. Livest. Prod. 18, 143-146.

Tosh, J.J. \& Kemp, R.A., 1994. Estimation of variance components of lamb weights in three sheep populations. J. Anim. Sci. 72, 1184-1190.

Van Wyk, J.B., Erasmus, G.J. \& Konstantinov, K.V. (1993). Variance components and heritability estimates of early growth traits in the Elsenburg Dormer sheep stud. S. Afr. J. Anim. Sci. 23, 72-76.

Yazdi, M.H., Engström, G., Näsholm, A., Johansson, K., Jorjani, H. \& Liljedahl, L-E. 1997. Genetic parameters for lamb weight at different ages and wool production in Baluchi sheep. Anim. Sci. 65, 247-255. 